\title{
A case of incomplete Kawasaki disease with extremely high serum ferritin and interleukin-18 levels
}

Takanori Noto ${ }^{1,2}$, Hiroki Seto ${ }^{1,2}$, Junji Fukuhara ${ }^{1,2}$, Masao Murabayashi, ${ }^{1,2}$, Akihiro Yachie $^{3}$, Mamoru Ayusawa $^{2}$ and Ichiro Morioka ${ }^{2 *}$ (D)

\begin{abstract}
Background: The clinical features and laboratory parameters of patients with Kawasaki disease (KD) and systemic juvenile idiopathic arthritis (sJIA) occasionally overlap. Therefore, serum levels of cytokine and ferritin are used as markers to distinguish between KD and sJIA. KD patients have a high level of interleukin (IL)-6, low level of IL-18, and no elevation of the level of serum ferritin. Conversely, sJIA patients have a low level of IL-6 and high levels of $\mathrm{IL}-18$ and ferritin in the serum. However, to the best of our knowledge, no case report of KD with a low serum level of IL-6 and extremely high levels of IL-18 and ferritin is found.
\end{abstract}

Case presentation: A 6-year-old boy presented with a history of fever for 9 days and a rash that appeared 7 days from the onset. He was diagnosed with incomplete KD because of fever, skin rash, oral cavity erythematous changes, and erythema and edema of the hands with laboratory findings of serum albumin level $<3.0 \mathrm{~g} / \mathrm{dL}$, elevated alanine aminotransferase level and leukocyturia. Intravenous immunoglobulin and prednisolone and oral aspirin were introduced on the 10th day. Fever subsided 1 day after initiating the treatment, but arthritis of both knees appeared in addition to hepatosplenomegaly. We suspected SJIA, as the serum level of ferritin was 19,740 ng/ $\mathrm{mL}$, IL- 6 was $<3 \mathrm{pg} / \mathrm{mL}$, and IL-18 was $132,000 \mathrm{pg} / \mathrm{mL}$. Skin desquamation of the fingertips was observed 18 days from the onset; thus, he was finally diagnosed with incomplete KD with arthritis. At 32 days from the onset, we stopped the prednisolone therapy and no symptoms of relapse were observed afterwards. In the follow-up at 16 months from the onset, he had neither signs of active joint or skin involvement, nor cardiac involvement.

Conclusions: Although patients with SJIA generally have high serum levels of IL-18 and ferritin, this was a case of incomplete KD with extremely high serum levels of IL-18 and ferritin. Serum cytokine and ferritin are often used for the differential diagnosis of KD and SJIA. We need to recognize the existence of KD with high serum levels of IL-18 and ferritin.

Keywords: Ferritin, Interleukin-6, Interleukin-18, Kawasaki disease, Systemic juvenile idiopathic arthritis

\section{Background}

Classic Kawasaki disease (KD) is clinically diagnosed based on the five following symptoms: the continuity of fever for at least 5 days, oral cavity erythematous changes (cracked lips, strawberry tongue), bilateral bulbar conjunctival injection, skin rash (maculopapular, diffuse erythroderma, or erythema multiforme-like), erythema and edema of the

\footnotetext{
* Correspondence: morioka.ichiro@nihon-u.ac.jp

${ }^{2}$ Department of Pediatrics and Child Health, Nihon University School of Medicine, 30-1, Oyaguchi, Kami-cho, Itabashi-ku, Tokyo 173-8610, Japan Full list of author information is available at the end of the article
}

hands and feet, and cervical lymphadenopathy (usually unilateral) [1]. Incomplete $\mathrm{KD}$ has also been known as one type of $\mathrm{KD}$, which is diagnosed based on fever more than 5 days with two or three of the five aforementioned symptoms or fever for $\geq 7$ days without other explanations, and compatible laboratory or echocardiographic findings $[1,2]$. Desquamation of the periungual region in the fingers usually begins in 2 to 3 weeks after the onset of fever. Some patients with KD develop arthritis, and the frequency of this condition is reported as 7.5-16\% [2-4]. Systemic juvenile idiopathic arthritis (sJIA) is characterized by

(c) The Author(s). 2018 Open Access This article is distributed under the terms of the Creative Commons Attribution 4.0 International License (http://creativecommons.org/licenses/by/4.0/), which permits unrestricted use, distribution, and reproduction in any medium, provided you give appropriate credit to the original author(s) and the source, provide a link to the Creative Commons license, and indicate if changes were made. The Creative Commons Public Domain Dedication waiver (http://creativecommons.org/publicdomain/zero/1.0/) applies to the data made available in this article, unless otherwise stated. 
remitting fever, a typical skin rash, and arthritis. Diagnosis of sJIA is often challenging, particularly before patients have the symptoms for 6 weeks as shown by the International League of Associations for Rheumatology and American College of Rheumatology criteria [5]. Given that the clinical features, especially in arthritis, in patients with incomplete KD and sJIA sometimes overlap, cytokines [6-10] and ferritin [11] in serum are used as markers to distinguish KD from sJIA. KD patients have a high interleukin (IL)-6 level and low IL-18 and ferritin levels in their serum. Conversely, sJIA patients have a low IL-6 level and high IL-18 and ferritin levels [6-11]. Contrary to these facts, however, we report for the first time a case of incomplete KD with a low serum IL-6 level and extremely high serum IL-18 and ferritin levels with written informed consent from the parents of the patient.

\section{Case presentation}

A 6-year-old boy was referred to our hospital due to a 9-day history of fever. On day 3 of illness, a diffuse maculopapular rash appeared. He was orally treated with cefcapene pivoxil prescribed by his family pediatrician. On admission, his weight and height were $24 \mathrm{~kg}$ and $124 \mathrm{~cm}$, respectively. He had a temperature of $38.9^{\circ} \mathrm{C}$ and had a diffuse maculopapular rash. His lips, hands, and feet were erythematous. In addition, he also developed hepatosplenomegaly and had pitting edema in his feet. There was no history or findings of conjunctival injection and cervical lymphadenopathy.

His clinical course is shown in Fig. 1. Blood examination revealed the following: white blood cell count of $12,800 / \mu \mathrm{L}$ (neutrophils, lymphocytes, and monocytes were 88,9 , and $3 \%$, respectively). C-reactive protein of $5.85 \mathrm{mg} / \mathrm{dL}$; hemoglobin level of $11.7 \mathrm{~g} / \mathrm{dL}$; and platelet count of $26.6 \times 10^{4} / \mu \mathrm{L}$. Other blood findings were as follows: serum albumin of $2.7 \mathrm{~g} / \mathrm{dL}$, total bilirubin of 0.7 $\mathrm{mg} / \mathrm{dL}$, sodium of $131 \mathrm{mEq} / \mathrm{L}$, potassium of $3.1 \mathrm{mEq} / \mathrm{L}$, aspartate aminotransferase of $100 \mathrm{IU} / \mathrm{L}$, alanine aminotransferase of $87 \mathrm{IU} / \mathrm{L}$, lactate dehydrogenase of $613 \mathrm{IU} /$ $\mathrm{L}$, and ferritin of $19,740 \mathrm{ng} / \mathrm{mL}$. His urinalysis showed leukocyturia without any bacteria (10-14 white blood cells/high power field). His chest radiograph showed normal findings. Echocardiography revealed a normal ejection fraction, but perivascular echo brightness of the coronary arteries was found.

Given that his clinical symptoms did not fulfill the diagnostic criteria for classic KD, he was diagnosed with an incomplete KD according to the American Heart Association guideline [2]. Therefore, intravenous immunoglobulin (IVIG, $2 \mathrm{~g} / \mathrm{kg} /$ dose), intravenous prednisolone (PSL, $2 \mathrm{mg} / \mathrm{kg} /$ day), and oral aspirin $(30 \mathrm{mg} / \mathrm{kg} /$ day) were administered on the 10th day of illness. In addition to IVIG, PSL was used for his treatments to prevent coronary artery abnormalities based on the result of RAISE study [12]. His temperature returned to normal soon after the first IVIG therapy was completed. On the 12th day of illness, however, he showed symptoms of arthritis in both knee joints, which led to a gait disturbance. sJIA was suspected based on the appearance of arthritis and an extremely high level of serum ferritin. To distinguish KD from sIIA, serum IL-6 and IL-18 levels were examined during that time. The serum levels of IL- 6 and IL-18 were extremely low and high, respectively (Fig. 1 and Table 1). Given the markedly elevated serum ferritin

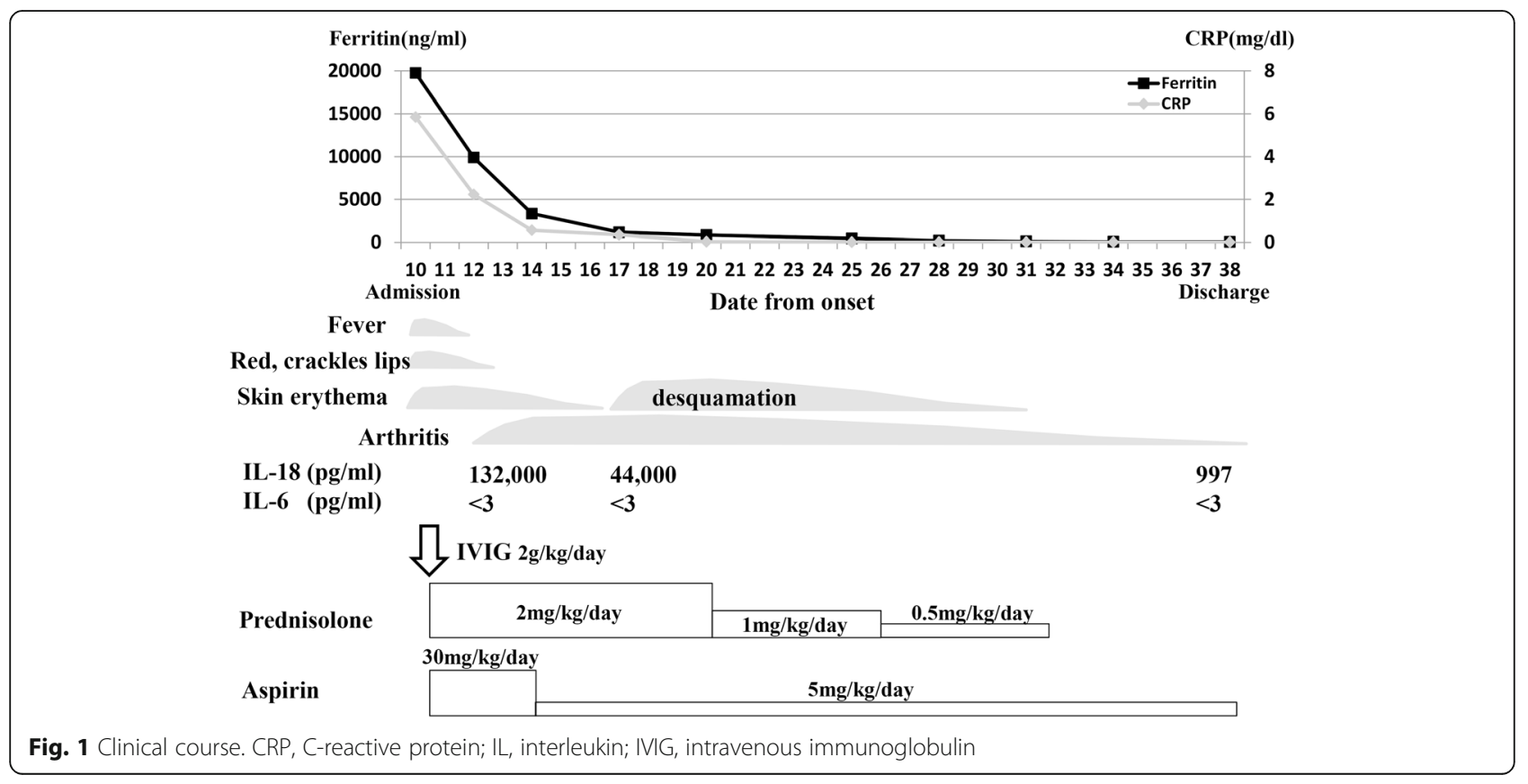


Table 1 Serum ferritin, IL-18, and IL-6 levels of our case and the reference levels

\begin{tabular}{llll}
\hline & Our case & KD & sJIA \\
\hline Ferritin, $\mathrm{ng} / \mathrm{mL}$ & 19,740 & $14-2376$ & $63-68,310$ \\
IL-18, pg/mL & 132,000 & $260-660$ & $10,860-330,000$ \\
IL-6, pg/mL & $<3$ & $106-1200$ & $7-580$ \\
\hline
\end{tabular}

The reference values of ferritin in KD and sJIA are from Mizuta et al. [11] and those of IL-18 and IL-6 are from Takahara et al. [7]

IL interleukin, KD Kawasaki disease, sJIA systemic juvenile idiopathic arthritis

and IL-18 levels, we suspected sJIA rather than incomplete KD. However, his rheumatoid factor and anti-nuclear antibody were negative. On the 17th day of illness, the elevated serum IL-18 level persisted (44,000 $\mathrm{pg} / \mathrm{mL}$ ) and his arthritis worsened. On the 18th day of illness, because skin desquamation of the fingertips occurred, he was diagnosed with incomplete KD. After the PSL treatment of $2 \mathrm{mg} / \mathrm{kg} / \mathrm{day}$ for 11 days, PSL was tapered to $1 \mathrm{mg} / \mathrm{kg} /$ day for 5 days and then $0.5 \mathrm{mg} / \mathrm{kg} /$ day for 5 days. On the 32nd day of illness, the PSL treatment was discontinued, as his joint symptoms were markedly improved. After the aspirin treatment of $30 \mathrm{mg} / \mathrm{kg} /$ day for 5 days, aspirin of $5 \mathrm{mg} / \mathrm{kg} /$ day was discontinued after 2 months of the disease onset. On the 116th day of illness, serum IL-18 level returned to normal. At 16 months after the disease onset, he had never shown any signs of joint or skin involvement and cardiac abnormalities including coronary arteries.

\section{Discussion and conclusions}

The clinical features and laboratory findings in some patients with incomplete KD and other systemic inflammatory diseases such as macrophage activation syndrome or sJIA overlap. No cytopenia, hypertriglyceridemia and hypofibrinogenemia were found in his clinical course (serum triglyceride level of $217 \mathrm{mg} / \mathrm{dL}$ and plasma fibrinogen level of $323 \mathrm{mg} / \mathrm{dL}$ ). There was no elevation of serum soluble interleukin-2 receptor level $(344 \mathrm{U} / \mathrm{mL})$. Based on these findings, because hemophagocytic lymphohistiocytosis was not suspected, a bone marrow examination was not performed for him. However, it has been reported that the patients who were considered as having refractory KD were finally diagnosed with sJIA [13]. Therefore, some serum markers have been proposed to distinguish KD from sJIA. Mizuta et al. reported that the serum ferritin level was significantly higher in SJIA patients than in KD patients, for which the cutoff value was $368.6 \mathrm{ng} / \mathrm{mL}$ [11]. In cytokines, the characteristics of serum markers in sJIA patients include significantly higher levels of IL-18 and lower levels of IL-6 than those in KD patients $[6,7,9,10]$. In our case, because extremely high serum ferritin and IL-18 levels, unelevated IL-6 levels, and arthritic symptoms were observed during the clinical course (Table 1), sJIA was suspected. However, we finally diagnosed the patient with incomplete KD accompanied with arthritis, because of the following reasons. First, perivascular echo brightness of the coronary arteries was found. Second, a periungual desquamation was observed during the recovery phase (Fig. 1). Third, his arthritis improved within 6 weeks, and the sJIA criteria were not completely fulfilled [14]. Fourth, the IVIG treatment was effective. Fifth, the disease improved during PSL treatment, and no relapse was found after the dose of PSL was tapered. Finally, his clinical symptoms were different from those of sJIA, such as flares of clinical signs and intermittent fever with rash. He looked so sick and agitated during the disease period, although patients with sJIA look almost normal during the intermittent afebrile period.

In conclusion, patients with sJIA generally have high serum IL-18 and ferritin levels [6-11]. This was a case of incomplete KD with extremely high serum levels of IL-18 and ferritin, although KD patients with coronary artery lesions have been reported to have mild IL-18 elevations [15]. Serum cytokines and ferritin are often used for the differential diagnosis of KD and sJIA. However, we should need to recognize the existence of KD in patients with high serum IL-18 and ferritin levels. Further studies are needed about the novel biomarkers to clearly distinguish sJIA from KD at an early phase of the disease progression.

\section{Abbreviations}

IL: Interleukin; IVIG: Intravenous immunoglobulin; KD: Kawasaki disease; PSL: Prednisolone; sJIA: systemic juvenile idiopathic arthritis

\section{Acknowledgments}

This research is supported by Japan Agency for Medical Research and Development, AMED (grant number: 18kk0205014s2103) and the Kawano Masanori Memorial Foundation for Promotion of Pediatrics.

\section{Funding}

Not applicable.

\section{Availability of data and materials}

The data used in this report are available from the corresponding author on reasonable request.

\section{Authors' contributions}

All authors contributed to the intellectual content of this manuscript and approved the final manuscript as submitted. TN and IM drafted the initial manuscript. TN, HS, JF, and MM cared the patient and collected the clinical samples or data. AY measured serum cytokine levels for this patient. TN, MM, $A Y, M A$, and IM interpreted the data. MA revised the article critically for important intellectual content.

Ethics approval and consent to participate

Ethics approval was obtained from the ethics committee in Numazu City Hospital (approval number 2018-0008). The patient's guardian provided the written informed consent to participate.

\section{Consent for publication}

We obtained the written consent for publication from the guardian of the patient.

\section{Competing interests}

All authors have no conflicts of interest to declare for this work. Outside the submitted work, I.M. has received grants from Japan Blood Product 
Organization, Daiichi Sankyo Co., Ltd., MSD Co., Ltd., AbbVie LLC, Taisho Toyama Pharmaceutical Co., Ltd., and Air Water Inc.; lecture fees from MSD Co., Ltd., Pfizer Japan, Inc., Novo Nordisk Pharma Ltd., Shionogi Co., Ltd., AbbVie LLC, Japan Vaccine Co., Ltd., Asahikasei Medical Co., Ltd., and Atom Medical Corp.; manuscript fees from Atom Medical Corp., Sanofi K.K., Asahikasei Medical Co., Ltd., and Japan Blood Product Organization, and honoraria from Sanofi K.K.

\section{Publisher's Note}

Springer Nature remains neutral with regard to jurisdictional claims in published maps and institutional affiliations.

\section{Author details}

'Department of Pediatrics, Numazu City Hospital, 550, Harunoki, Higashi-Shiroji, Numazu 4100302, Japan. ${ }^{2}$ Department of Pediatrics and Child Health, Nihon University School of Medicine, 30-1, Oyaguchi, Kami-cho, Itabashi-ku, Tokyo 173-8610, Japan. ${ }^{3}$ Department of Pediatrics, School of Medicine, Institute of Medical, Pharmaceutical and Health Sciences, Kanazawa University, 13-1, Takaramachi, Kanazawa 9208641, Japan.

Received: 4 September 2018 Accepted: 4 December 2018

Published online: 12 December 2018

\section{References}

1. McCrindle BW, Rowley AH, Newburger JW, Burns JC, Bolger AF, Gewitz M, et al. Diagnosis, treatment, and long-term management of Kawasaki disease: a scientific statement for health professionals from the American Heart Association. Circulation. 2017;135:e927-99.

2. Baker AL, Lu M, Minich LL, Atz AM, Klein GL, Korsin R, et al. Associated symptoms in the ten days before diagnosis of Kawasaki disease. J Pediatr. 2009;154:592-5.

3. Gong GW, McCrindle BW, Ching JC, Yeung RS. Arthritis presenting during the acute phase of Kawasaki disease. J Pediatr. 2006;148:800-5.

4. Álvarez EP, Rey F, Peña SC, Rubio A, Calvo C, Collado P. Has articular involvement lessened in Kawasaki disease? Rheumatol Clin. 2017;13:145-9.

5. Stabile A, Avallone L, Compagnone A, Ansuini V, Bertoni B, Rigante D. Focus on juvenile idiopathic arthritis according to the 2001 revised Edmonton classification from the international league of associations for rheumatology. Eur Rev Med Pharmacol Sci. 2006;10:229-34.

6. Shimizu M, Yokoyama T, Yamada K, Kaneda H, Wada H, Wada T, et al. Distinct cytokine profiles of systemic-onset juvenile idiopathic arthritis associated macrophage activation syndrome with particular emphasis on the role of interleukin-18 in its pathogenesis. Rheumatology. 2010;49:1645-53.

7. Takahara T, Shimizu M, Nakagishi Y, Kinjo N, Yachie A. Serum IL-18 as a potential specific marker for differentiating systemic juvenile idiopathic arthritis from incomplete Kawasaki disease. Rheumatol Int. 2015;35:81-4.

8. Xia Y, Cui P, Li Q, Liang F, Li C, Yang J. Extremely elevated IL-18 levels may help distinguish systemic-onset juvenile idiopathic arthritis from other febrile diseases. Braz J Med Biol Res. 2017:50:1414-31.

9. Nomura Y, Masuda K, Maeno N, Yoshinaga M, Kawano Y. Serum levels of interleukin-18 are elevated in the subacute phase of Kawasaki syndrome. Int Arch Allergy Immunol. 2004;135:161-5.

10. Maeno N, Takei S, Nomura Y, Imanaka H, Hokonohara M, Miyata K. Highly elevated serum levels of interleukin-18 in systemic juvenile idiopathic arthritis but not in other juvenile idiopathic arthritis subtypes or in Kawasaki disease. Arthritis Rheum. 2002:46:2539-41.

11. Mizuta M, Shimizu M, Inoue N, Kasai K, Nakagishi Y, Takahara T, et al. Serum ferritin levels as useful diagnostic marker for the distinction of systemic juvenile idiopathic arthritis and Kawasaki disease. Mod Rheumatol. 2016;26:929-32.

12. Kobayashi T, Saji T, Otani T, et al. Efficacy of immunoglobulin plus prednisolone for prevention of coronary artery abnormalities in severe Kawasaki disease (RAISE sturdy) : a randomized, open-label, blinedendpoints trial. Lancet. 2012;379:1613-20.

13. Rigante D, Valentini P, Onesimo R, Angelone DF, De Nisco A, Bersani G, et al. Incomplete Kawasaki syndrome followed by systemic onset juvenile idiopathic arthritis mimicking Kawasaki syndrome. Rheumatol Int. 2010;30:535-9.

14. Petty RE, Southwood TR, Manners P, Baum J, Glass DN, Goldenberg J, et al. International league of associations for rheumatology classification of juvenile idiopathic arthritis: second revision, Edmonton, 2001. J Rheumatol. 2004;31:390-2.

15. Wang KP, Hsieh KS, Huang SH, Ou SF, Lai TJ, Tang CW, et al. Interleukin-18 and coronary artery lesions in patients with Kawasaki disease. J Chin Med Assoc. 2013;76:438-45

Ready to submit your research? Choose BMC and benefit from:

- fast, convenient online submission

- thorough peer review by experienced researchers in your field

- rapid publication on acceptance

- support for research data, including large and complex data types

- gold Open Access which fosters wider collaboration and increased citations

- maximum visibility for your research: over $100 \mathrm{M}$ website views per year

At BMC, research is always in progress.

Learn more biomedcentral.com/submissions 